\title{
Effect of Cold-Rolled Thickness Reduction Degree on Characteristics of Hydrogen Diffusion in Silicon Steel
}

\author{
Yongfeng Li, ${ }^{1}$ Lian Cai, ${ }^{2}$ Guanjun Liu, ${ }^{1}$ and Lijie $\mathrm{Ma}^{1}$ \\ ${ }^{1}$ School of Mechanical and Electrical Engineering, Henan Institute of Science and Technology, East of Hualan Road, \\ Xinxiang 453003, China \\ ${ }^{2}$ College of Information, Mechanical and Electrical Engineering, Shanghai Normal University, 100 Guilin Road, \\ Shanghai 200235, China
}

Correspondence should be addressed to Yongfeng Li; lyf16816800@163.com

Received 6 January 2014; Revised 25 May 2014; Accepted 1 June 2014; Published 17 June 2014

Academic Editor: Michael J. Schütze

Copyright (C) 2014 Yongfeng Li et al. This is an open access article distributed under the Creative Commons Attribution License, which permits unrestricted use, distribution, and reproduction in any medium, provided the original work is properly cited.

The characteristic of hydrogen uptake and diffusion in the cold-rolled silicon steel was investigated by electrochemical hydrogen permeation technique performed under different cathodic charging current density and cold-rolled thickness reduction degree. The results indicated that anodic permeation current density increased with increasing cathodic charging current for the specimens. Moreover, the anodic steady state permeation current density and the solubility increased with an increase in the cold-rolled thickness reduction degrees. The breakthrough time of hydrogen in the specimens was shortened with increasing thickness reduction degrees, and the value of the hydrogen diffusivity decreased gradually with increasing thickness reduction degrees.

\section{Introduction}

Hydrogen is the most widely occurring element in the Universe and considered as the fuel of the future. It is readily available in abundance; therefore, in recent years, it is extensively used as a high-energy fuel. However, the entry of hydrogen into the metal surface is a serious problem encountered during many electrochemical processes, including corrosion of metals, pickling of metals, electroplating of metals, and metal welding [1-3]. The hydrogen which is introduced into the metal via electrochemical process or gaseous absorption leads to hydrogen embrittlement of the material which results in the decrease in the mechanical properties such as toughness and ductility. Moreover, hydrogen embrittlement even results in hydrogen induced cracking or brittle fracture [4-6] which finally causes the failure of the material. A component or structure can be contaminated by hydrogen in various stages of its life [7]. Hydrogen degradation significantly affects various industrial branches because it leads to dangerous failures and loss of property.

Silicon steel is specialty steel tailored to produce certain magnetic properties. The addition of silicon to steel increases its electrical resistance, improves the ability of magnetic fields to penetrate it, and reduces the steel's hysteresis loss. After hot rolling or cold rolling process of silicon steel, it usually requires pickling process for the removal of the surface oxide. Pickling of metal is essentially a process involving the removal of an oxide layer by hydrogen generated by the chemical reaction between metal or metal oxide and acid. Therefore, pickling process is often accompanied by the generation of hydrogen. Silicon steel is highly susceptible to hydrogen embrittlement which is influenced by diffusion characteristics of hydrogen in silicon steel. Takahashi et al. [8] and Marrow et al. [9] also confirmed that, when silicon steel is in hydrogen environment, hydrogen exhibits significant influence on crack initiation and expansion of the material. Therefore, it is extremely important and highly desirable to study the specific diffusion characteristic of hydrogen in silicon steel and to investigate the diffusion ability of hydrogen in silicon steel. Detailed information about the kinetics of hydrogen adsorption, entry, and transport is essentially required to understand the factors controlling the hydrogen embrittlement in silicon steel. High-temperature vacuum vapor permeation and electrochemical hydrogen permeation methods are usually used to evaluate diffusion 
TABLE 1: Chemical composition of silicon steel, wt\%.

\begin{tabular}{lcccccc}
\hline Element & $\mathrm{C}$ & $\mathrm{Si}$ & $\mathrm{Mn}$ & $\mathrm{P}$ & $\mathrm{S}$ & $\mathrm{Fe}$ \\
\hline Percentage (\%) & 0.011 & 0.400 & 0.506 & 0.070 & 0.001 & Balance \\
\hline
\end{tabular}

characteristic of hydrogen in the material [10-13]. In hightemperature vacuum vapor permeation method, there is a high pressure difference on both sides of the material. When molecular hydrogen permeates from the high pressure to the low pressure side, the permeated molecular hydrogen could be detected; thus, the kinetics of hydrogen permeation process could be obtained. However, the experimental device is extremely complex, and the test costs are relatively high. In contrast, the electrochemical permeation method is extremely convenient because it involves simple and inexpensive electrochemical device and high testing sensitivity and versatility at room temperature. The electrochemical hydrogen permeation method was proposed by Devanathan and Stachurski [14]; it has been widely used to investigate the diffusion coefficient of hydrogen in the material and embrittlement phenomenon of metals. In this study, coldrolled silicon steel sheets were used as specimen to evaluate the effect of cold-rolled thickness reduction degree on hydrogen diffusion in silicon steel. Electrochemical hydrogen permeation method was utilised to measure the diffusion characteristic of hydrogen in silicon steel under different cathodic charging current or different cold-rolled thickness reduction degree.

\section{Experimental Procedures}

2.1. Material and Specimen Preparation. Commercially available silicon steel with a thickness of $2.7 \mathrm{~mm}$ was used in this study. The chemical composition of the as-received silicon steel is listed in Table 1. The specimens were cold rolled by a rolling machine. By adjusting the amount of coldrolled thickness reduction on the rolling machine, three types of cold-rolled specimens were obtained, with cold-rolled thickness reduction degrees of $54.8,72.2$, and $77.4 \%$, and the corresponding thickness of the three samples was $1.48,0.75$, and $0.61 \mathrm{~mm}$, respectively. The microstructures of the coldrolled silicon steel with different thickness reduction degrees were observed by optical microscope.

The specimens with dimensions of $50 \mathrm{~mm} \times 70 \mathrm{~mm}$ and effective surface area of $9 \mathrm{~cm}^{2}$ were used in this study. First, the specimen was mechanically polished successively with $600,1,000$, and 1,200 grade abrasive papers. Second, the specimen was cleaned in an ultrasonic cleaning bath, rinsed with distilled water, and dried rapidly by cold air blowing. Finally, one side of each specimen was plated with nickel (Ni) to a thickness of $1 \mu \mathrm{m}$ to avoid dissolution of the specimen which may affect the permeation experiment data.

2.2. Electrochemical Hydrogen Permeation. Hydrogenation of the specimens was necessary to investigate the tendency of the silicon steel toward hydrogen embrittlement. The electrochemical hydrogen permeation technique involving a Devanathan-Stachurski twin or double electrolytic cell was

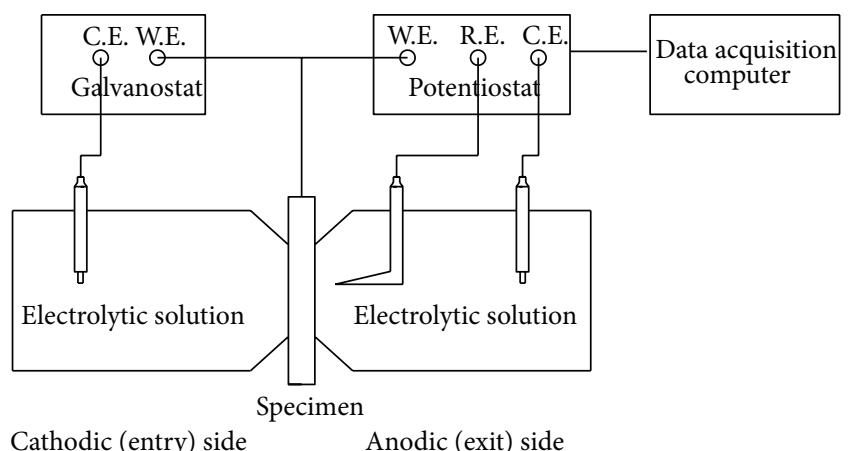

FIGURE 1: The schematic diagram of the experimental setup for hydrogen permeation experiment.

used to determine the diffusion of hydrogen in steel materials. Figure 1 shows the schematic representation of the experimental set up for hydrogen permeation. This experimental set up is extensively employed to determine the hydrogen permeation rate through metallic membranes. One side of the specimen acts as the cathode for the cathodic chamber, and the other side acts as the anode (anodic chamber). The anode (exit) side was coated with $\mathrm{Ni}$ to make it corrosion resistant. A constant potential of $300 \mathrm{mV}$ versus Ni electrode was applied on the anode side prior to the beginning of the permeation experiment. The cathode side charged hydrogen until the background current density was reduced to below $0.1 \mu \mathrm{A} \mathrm{cm}^{-2}$ at the anode side. Hydrogen charging current density was 5,10 , and $30 \mathrm{~mA} \mathrm{~cm}^{-2}$, respectively. The cathode hydrogen charging could produce a lot of hydrogen atoms on the surface of the cathode. The hydrogen is then adsorbed on the surface of the specimen and atomically absorbed into the bulk of the material. When hydrogen atoms arrived at the surface of the anode, they were oxidized by the anodic potential and the anodic hydrogen permeation current was obtained. Further, the cathodic charging and the electrochemical workstation were switched off until the permeation current density acquired a steady level. Both chambers were maintained at a constant temperature of $25 \pm 1^{\circ} \mathrm{C}$ throughout the experiment.

2.3. Data Analysis. For the electrochemical hydrogen permeation technique, the permeation flux of hydrogen through the specimen was determined from the steady state permeation current density $\left(i_{p}^{\infty}\right)$, and it is represented as follows:

$$
J_{\infty}=\frac{i_{p}^{\infty}}{n F}
$$

where $J_{\infty}$ is atomic hydrogen permeation flux at steady state $\left(\mathrm{mol} \mathrm{cm} \mathrm{s}^{-2}\right), i_{p}^{\infty}$ is permeation current density at steady state $\left(\mathrm{A} \mathrm{cm}^{-2}\right), n$ is the number of electrons transferred (dimensionless), and $F$ is Faraday's constant $\left(96,485 \mathrm{C} \mathrm{mol}^{-1}\right)$.

The theoretical equation for hydrogen diffusion [15] is

$$
\frac{i_{p}}{i_{p}^{\infty}}=\frac{2 L}{\sqrt{\pi D t}} \sum_{n=0}^{\infty} \exp \left[-\frac{(2 n+1)^{2} L^{2}}{4 D t}\right]
$$


where $D$ is a constant, $\mathrm{cm}^{2} \mathrm{~s}^{-1}$, and the effective hydrogen diffusivity $\left(D_{\text {eff }}\right)$ could be determined by fitting the model equation (2) into the experimental permeation curve.

The apparent hydrogen solubility $S$ is obtained [16] by using (3) when the surface hydrogen was in thermodynamic equilibrium with subsurface hydrogen:

$$
S=\frac{J_{\infty} L}{D_{\mathrm{eff}}},
$$

where $S$ is the apparent hydrogen solubility $\left(\mathrm{mol} \mathrm{cm}^{-3}\right)$ and $L$ is the specimen thickness $(\mathrm{cm})$.

\section{Results and Discussion}

3.1. Effect of Cathodic Hydrogen Charging Current on Hydrogen Diffusion. To investigate the effect of cathodic hydrogen charging current on hydrogen diffusion, different current densities $\left(5,10\right.$, and $\left.30 \mathrm{~mA} \mathrm{~cm}^{-2}\right)$ were employed on the cathode side under galvanostatic conditions (constant current density), which correspond to different hydrogen permeation curve at anode side as shown in Figure 2. The thickness of the specimens was $0.61 \mathrm{~mm}$. Figure 2 shows that the permeation current density at steady state increases with increasing charging current density. This is attributed to the fact that higher currents lead to the evolution of more hydrogen atoms on the surface of cathode which increases the amount of diffusible hydrogen and thereby enhances the ionised current density at the anode. Moreover, Figure 2 also exhibits that, with the increasing cathodic charging current density, the rate of diffusion of hydrogen in the specimen also gets accelerated. Furthermore, Figure 3 demonstrates that the time of breakthrough of hydrogen atoms from the entry to the exit is the shortest at the charging current density of $30 \mathrm{~mA} \mathrm{~cm}^{-2}$. In contrast, the time is the longest for the charging current density of $5 \mathrm{~mA} \mathrm{~cm}^{-2}$. This is mainly because the cathodic charging current was initially used to remove the oxide film from the surface of the cathode. Therefore, the higher is the cathodic charging current, the shorter is the removal time. Consequently, the diffusion rate of hydrogen in the specimens is significantly accelerated with an increase in hydrogen charging current density at the cathode.

\subsection{Effect of Thickness Reduction Degrees on Hydrogen Diffu-} sion. Figure 4 shows the microstructures of silicon steel cold rolled to different thickness reduction degrees indicating that cold rolling not only changes the shape and size of the plate but also changes the internal structure. With the increase in cold-rolled thickness reduction degree, the grains in the specimens are gradually elongated and flattened, and the slip direction of the grains turned to the rolling direction. The grains become almost fibrous at higher thickness reduction degree.

Effect of the specimen's thickness on the characteristic of hydrogen diffusion was investigated by hydrogen permeation experiments. The cathodic charging current density was $10 \mathrm{~mA} \mathrm{~cm}^{-2}$ and the silicon steel plates with thickness of

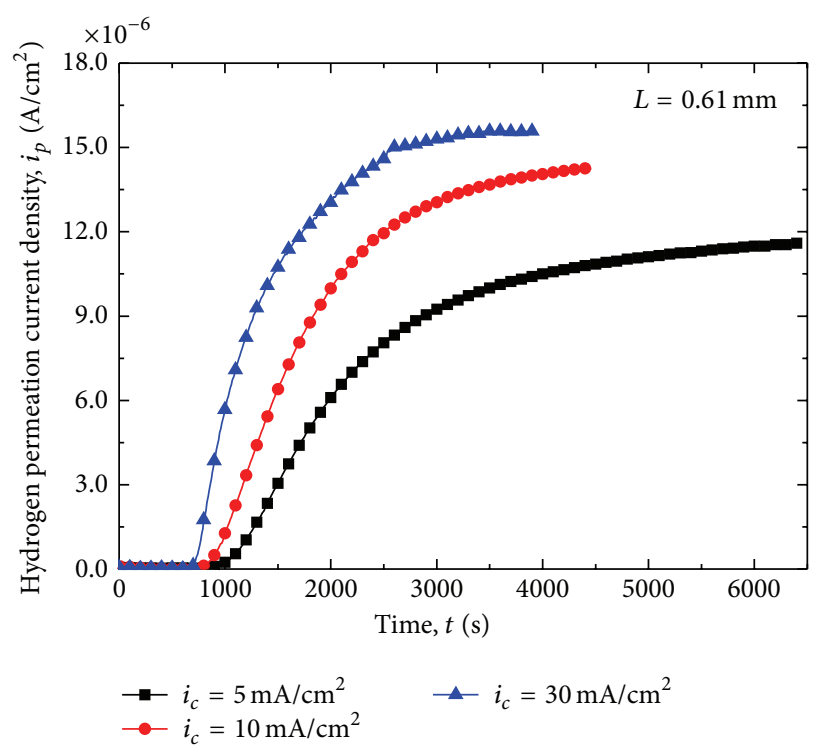

FIGURE 2: Hydrogen permeation curves for the silicon steel with the same thickness under different hydrogen charging current density.

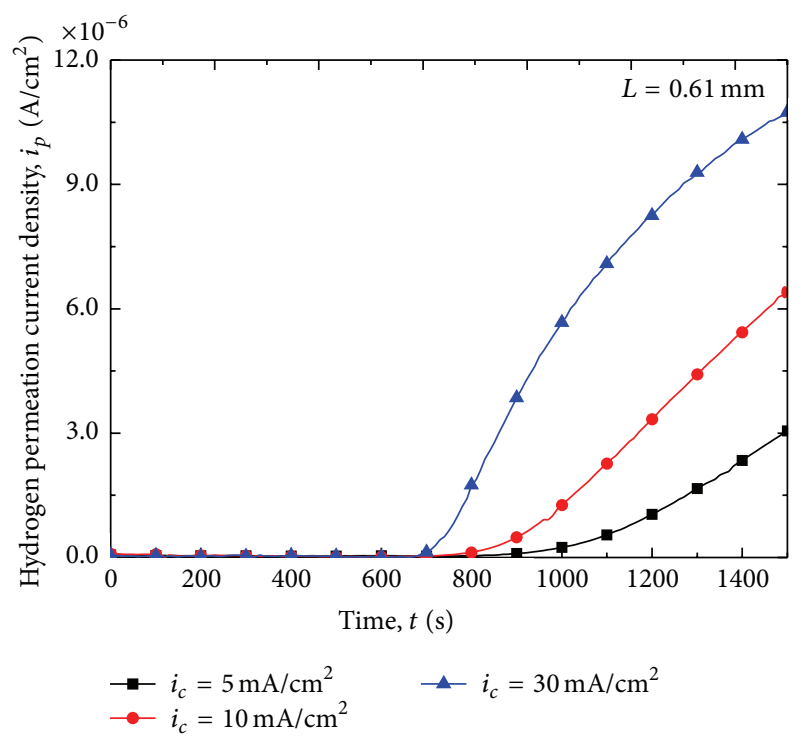

FIGURE 3: Hydrogen permeation curves under different hydrogen charging current density at initial charging stage.

$2.7,1.48,0.75$, and $0.61 \mathrm{~mm}$ were used in the experiment. Figure 5 exhibits the curves corresponding to the experimental results revealing that the permeation current density at steady state decreases significantly with the increase in the thickness of the specimens. These results indicate that the diffusion parameters are a function of the plate thickness. With the increase in the plate thickness, the values of the diffusible parameter of hydrogen in the specimens decrease. For the silicon steel plate with thickness of $0.61 \mathrm{~mm}$, when the hydrogen diffusion reaches a steady state, the measured value of steady state permeation current density is $1.42 \times$ $10^{-5} \mathrm{~A} \mathrm{~cm}^{-2}$ at the anode side. The steady state permeation 

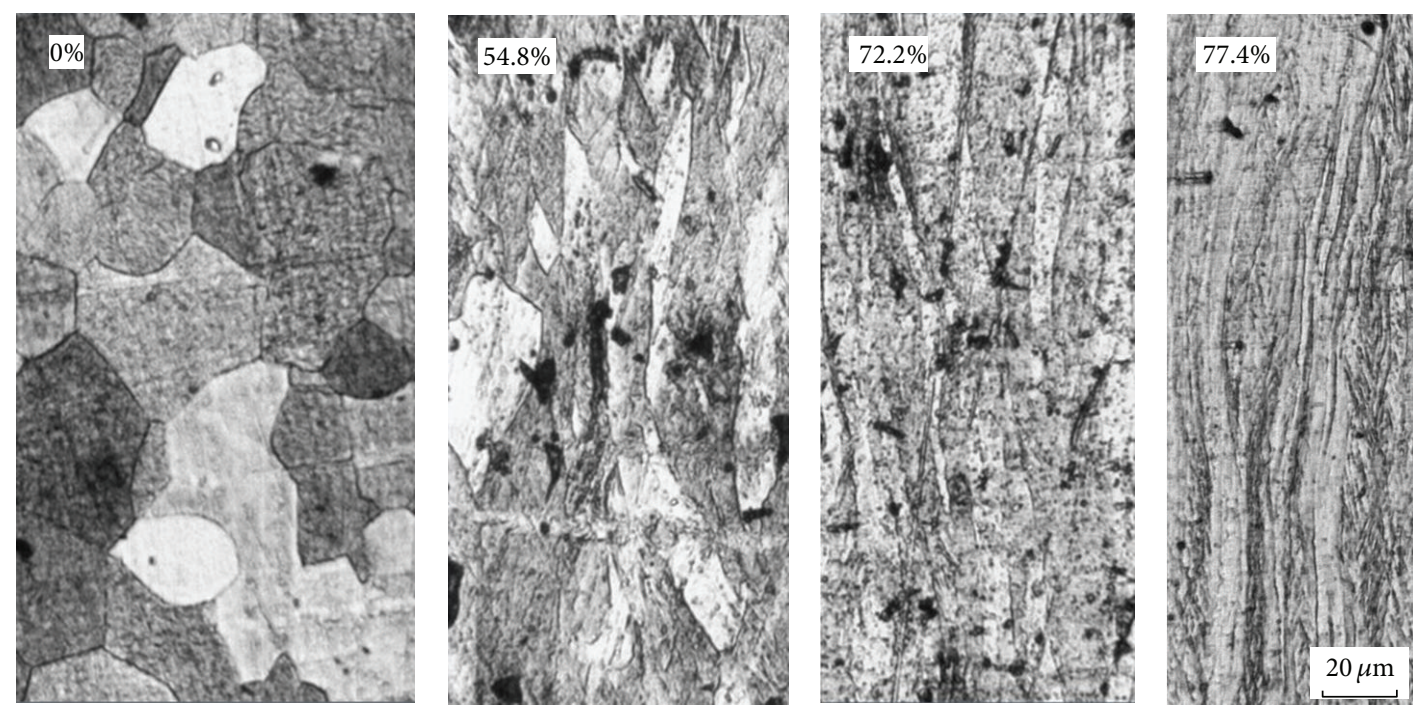

Figure 4: Microstructures of silicon steel cold rolled to different thickness reduction degrees.

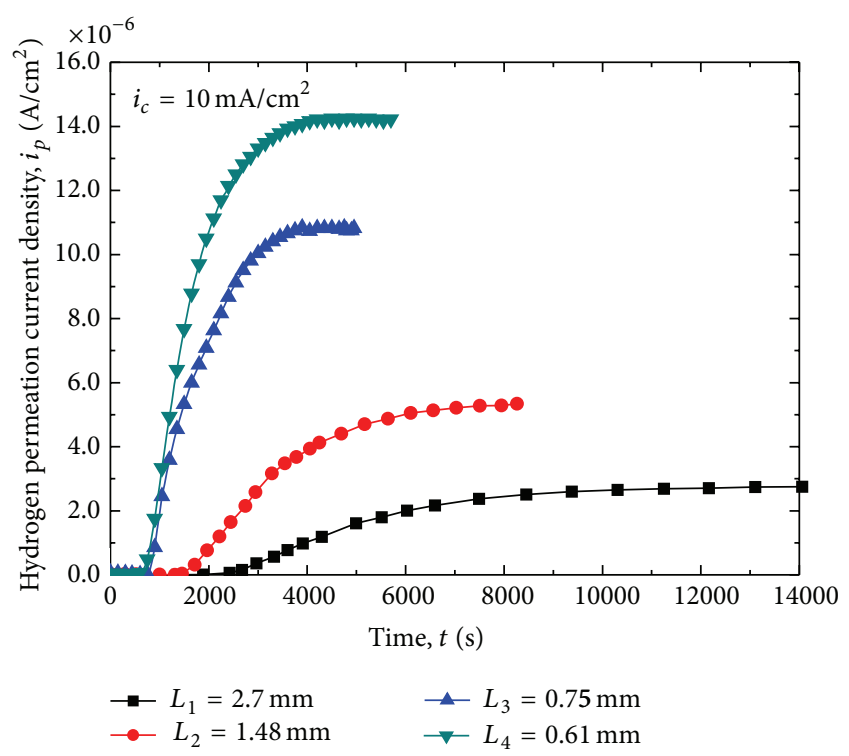

FIGURE 5: Hydrogen permeation curves for different thickness of the silicon steel under the same hydrogen charging current density.

current density is $1.08 \times 10^{-5} \mathrm{~A} \mathrm{~cm}^{-2}$ for the silicon steel plate with thickness of $0.75 \mathrm{~mm}$. When the plate thickness is increased to 1.48 or $2.7 \mathrm{~mm}$, the anode steady state permeation current density is reduced to $5.68 \times 10^{-6}$ and $2.73 \times 10^{-6} \mathrm{~A} \mathrm{~cm}^{-2}$, respectively. Figure 6 shows the hydrogen permeation curves for different thickness of the silicon steel at initial charging stage demonstrating that, when the specimen thickness increases, the breakthrough time of hydrogen in the specimen also increases. When the thickness of the silicon steel plate is $0.61 \mathrm{~mm}$, the breakthrough time of hydrogen in the specimen is about $600 \mathrm{~s}$; however, the breakthrough time of hydrogen in the specimen is about $750 \mathrm{~s}$ for the specimen with the thickness of $0.75 \mathrm{~mm}$. When the thickness of the

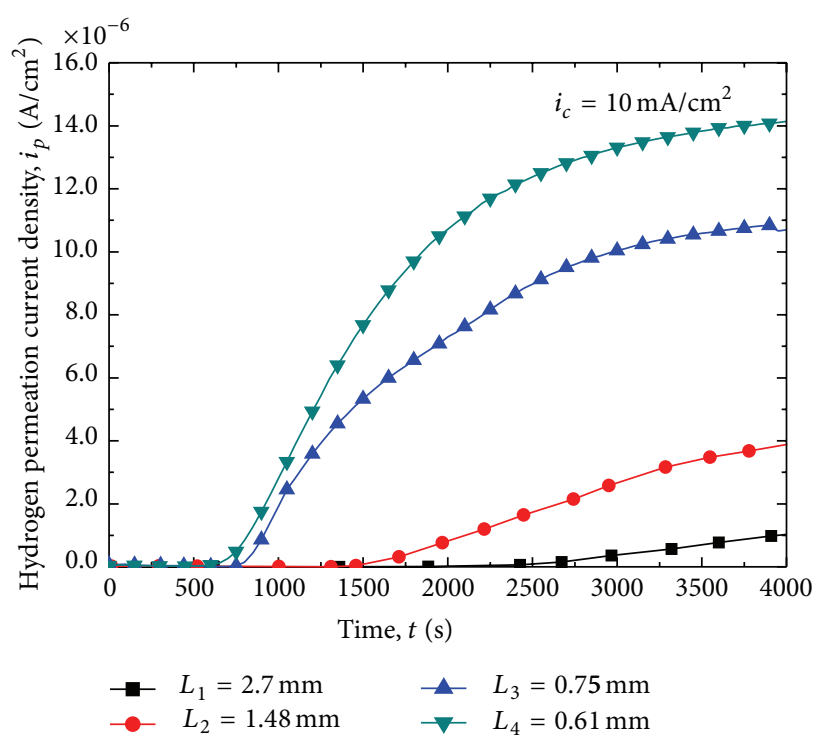

FIGURE 6: Hydrogen permeation curves for different thickness of the silicon steel at initial charging stage.

specimen is increased to 1.48 or $2.7 \mathrm{~mm}$, the breakthrough time of hydrogen in the specimen is increased to $\sim 1,456$ and $2,493 \mathrm{~s}$, respectively. Therefore, the breakthrough time for the thicker membrane is inherently longer. Figure 6 shows that the latter factor predominates.

3.3. Effect of Thickness Reduction Degrees on Hydrogen Diffusivity and Solubility. The analysis of the curves (Figure 5) corresponding to the experimental results enabled us to determine the diffusivity $\left(D_{\text {eff }}\right)$ by fitting hydrogen diffusion theoretical equation (2) into these curves. The apparent solubility of hydrogen measured in silicon steel is defined by using (3). The values of cold-rolled thickness reduction degrees and corresponding diffusivity and solubility of hydrogen are listed 
TABLE 2: Cold-rolled thickness reduction degree and corresponding diffusivity and solubility of hydrogen.

\begin{tabular}{lccc}
\hline Thickness $(\mathrm{mm})$ Thickness reduction & $D_{\text {eff }}\left(\mathrm{cm}^{2} \mathrm{~s}^{-1}\right)$ & $S\left(\mathrm{~mol} \mathrm{~cm}^{-3}\right)$ \\
\hline 2.70 & 0.0 & $2.17 \times 10^{-6}$ & $3.56 \times 10^{-6}$ \\
1.48 & $54.8 \%$ & $1.02 \times 10^{-6}$ & $8.04 \times 10^{-6}$ \\
0.75 & $72.2 \%$ & $4.55 \times 10^{-7}$ & $1.60 \times 10^{-5}$ \\
0.61 & $77.4 \%$ & $3.70 \times 10^{-7}$ & $2.43 \times 10^{-5}$ \\
\hline
\end{tabular}

in Table 2. As the thickness of the specimens decreased from 2.7 to $0.61 \mathrm{~mm}$, the value of the hydrogen diffusivity decreased gradually from $2.17 \times 10^{-6}$ to $3.70 \times 10^{-7} \mathrm{~cm}^{2} \mathrm{~s}^{-1}$; however, the value of the solubility increased gradually from $3.56 \times 10^{-6}$ to $2.43 \times 10^{-5} \mathrm{mulch}^{-3}$. This phenomenon indicated that the hydrogen population was mainly governed by the trapping of hydrogen when it was transported through the specimens, which mainly occurred at the grain boundaries.

\section{Conclusions}

The electrochemical permeation technique was adopted in this study and the characteristic of hydrogen diffusion in silicon steel under different cathodic hydrogen charging current or cold-rolled thickness reduction degrees was investigated. The results indicated that measured permeation current density increased with an increase in cathodic charging current density for the same thickness. With increasing cold-rolled thickness reduction degrees, the grains in the specimens were gradually elongated and flattened, the slip direction of the grains turned to the rolling direction, the anodic steady state permeation current density significantly increased, and the breakthrough time of hydrogen in the specimen was shortened. Moreover, hydrogen diffusivity decreased gradually; however, the solubility gradually increased.

\section{Conflict of Interests}

The authors declare that there is no conflict of interests regarding the publication of this paper.

\section{Acknowledgments}

The authors gratefully acknowledge the financial supports from Research Program of Foundation and Advanced Technology of Henan Province of China (no. 142300410016), the Scientific Research Starting Foundation for High-level Talents in Henan Institute of Science and Technology (no. 2012028), and Shanghai Normal University under Contract SK201224.

\section{References}

[1] H. Kim, B. N. Popov, and K. S. Chen, "Comparison of corrosionresistance and hydrogen permeation properties of $\mathrm{Zn}-\mathrm{Ni}, \mathrm{Zn}$ $\mathrm{Ni}-\mathrm{Cd}$ and Cd coatings on low-carbon steel," Corrosion Science, vol. 45, no. 7, pp. 1505-1521, 2003.
[2] A. Gajek and T. Zakroczymski, "Long-lasting hydrogen evolution on and hydrogen entry into iron in an aqueous solution," Journal of Electroanalytical Chemistry, vol. 578, no. 1, pp. 171182, 2005.

[3] M. Ramasubramanian, B. N. Popov, and R. E. White, "Characterization of hydrogen permeation through zinc-nickel alloys under corroding conditions mathematical model and experimental study," Journal of the Electrochemical Society, vol. 145, no. 6, pp. 1907-1913, 1998.

[4] V. G. Gavriljuk, A. V. Tarasenko, and A. S. Tereshchenko, "Phase transformations and relaxation phenomena induced by hydrogen in austenitic stainless steels," International Journal of Hydrogen Energy, vol. 22, no. 2-3, pp. 269-277, 1997.

[5] Y. Li, L. Zhao, W. Kan, and H. Pan, "Phase transformations and micro cracks induced by hydrogen in cold-rolled and annealed AISI 304 stainless steels," International Journal of Hydrogen Energy, vol. 37, no. 10, pp. 8724-8728, 2012.

[6] Y.-S. Choi and J.-G. Kim, "Stress corrosion cracking and hydrogen embrittlement cracking of welded weathering steel and carbon steel in a simulated acid rain environment," Materials Science and Technology, vol. 19, no. 12, pp. 1737-1745, 2003.

[7] J. Ćwiek, "Hydrogen degradation of high-strength steels," Journal of Achievements in Materials and Manufacturing Engineering, vol. 37, no. 2, pp. 193-212, 2009.

[8] Y. Takahashi, K. Yamaguchi, M. Tanaka, K. Higashida, and H. Noguchi, "On the micromechanism of hydrogen-assisted cracking in a single-crystalline iron-silicon alloy thin sheet," Scripta Materialia, vol. 64, no. 6, pp. 537-540, 2011.

[9] T. J. Marrow, M. Aindow, P. Prangnell, M. Strangwood, and J. F. Knott, "Hydrogen-assisted stable crack growth in iron-3 WT\% silicon steel," Acta Materialia, vol. 44, no. 8, pp. 3125-3140, 1996.

[10] T. Akamatsu, Y. Kume, K. Komiya, H. Yukawa, M. Morinaga, and S. Yamaguchi, "Electrochemical method for measuring hydrogen permeability through metals," Journal of Alloys and Compounds, vol. 393, no. 1-2, pp. 302-306, 2005.

[11] H. Addach, P. Berçot, M. Rezrazi, and M. Wery, "Hydrogen permeation in iron at different temperatures," Materials Letters, vol. 59, no. 11, pp. 1347-1351, 2005.

[12] D. Levchuk, F. Koch, H. Maier, and H. Bolt, "Deuterium permeation through Eurofer and $\alpha$-alumina coated Eurofer," Journal of Nuclear Materials, vol. 328, no. 2-3, pp. 103-106, 2004.

[13] D. Levchuk, F. Koch, H. Maier, and H. Bolt, "Gas-driven deuterium permeation through $\mathrm{Al}_{2} \mathrm{O}_{3}$ coated samples," in Proceedings of the International Topical Conference on Hydrogen in Condensed Matter, pp. 119-123, Institute of Physics Publishing, June 2003.

[14] M. Devanathan and Z. Stachurski, "The adsorption and diffusion of electrolytic hydrogen in palladium," Proceedings of the Royal Society A, vol. 270, no. 90, pp. 90-102, 1962.

[15] J. McBreen, L. Nanis, and W. Beck, "A method for determination of the permeation rate of hydrogen through metal membranes," Journal of the Electrochemical Society, vol. 113, no. 11, pp. 1218$1222,1966$.

[16] H. Addach, P. Berçot, M. Rezrazi, and J. Takadoum, "Study of the electrochemical permeation of hydrogen in iron," Corrosion Science, vol. 51, no. 2, pp. 263-267, 2009. 

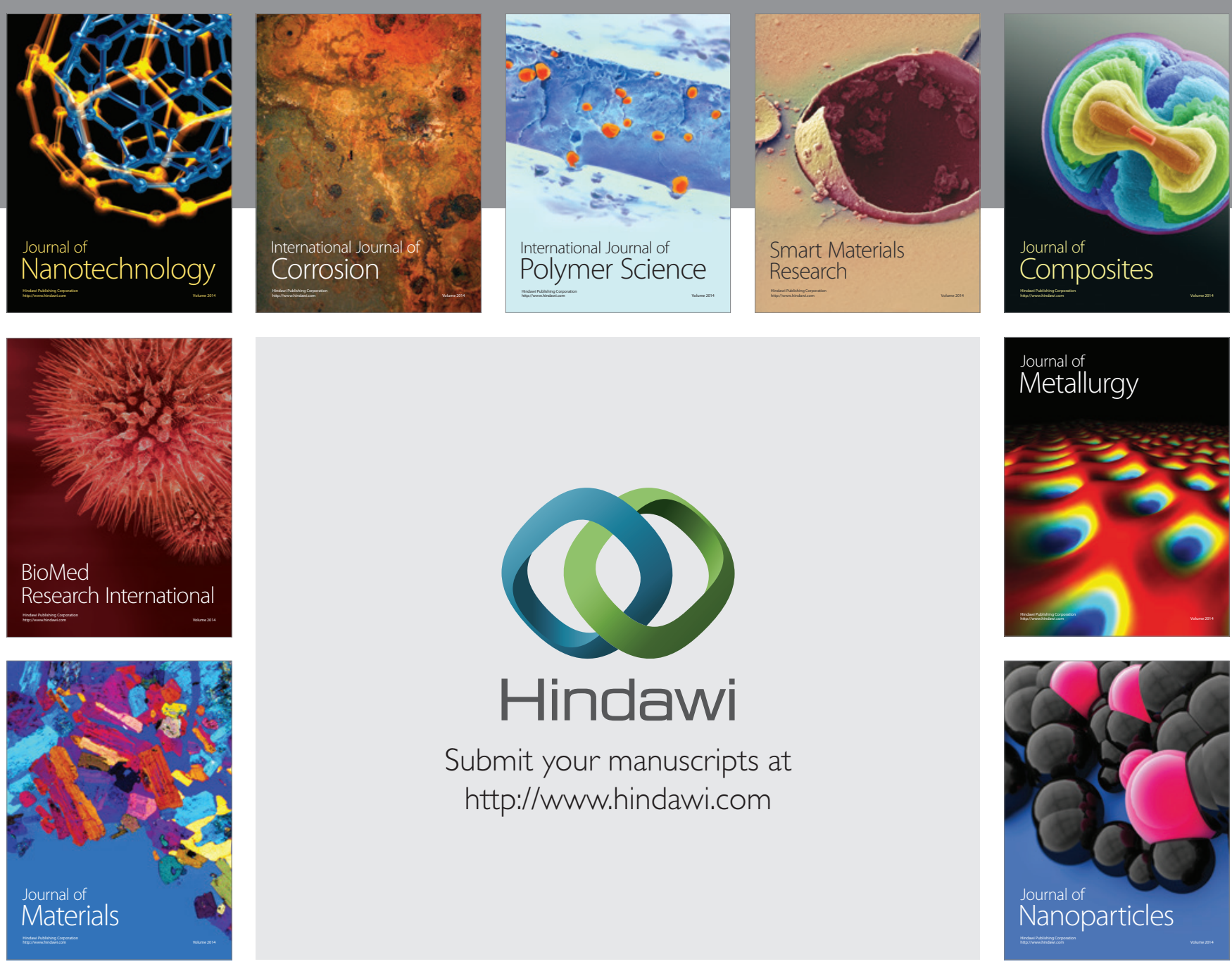

Submit your manuscripts at http://www.hindawi.com
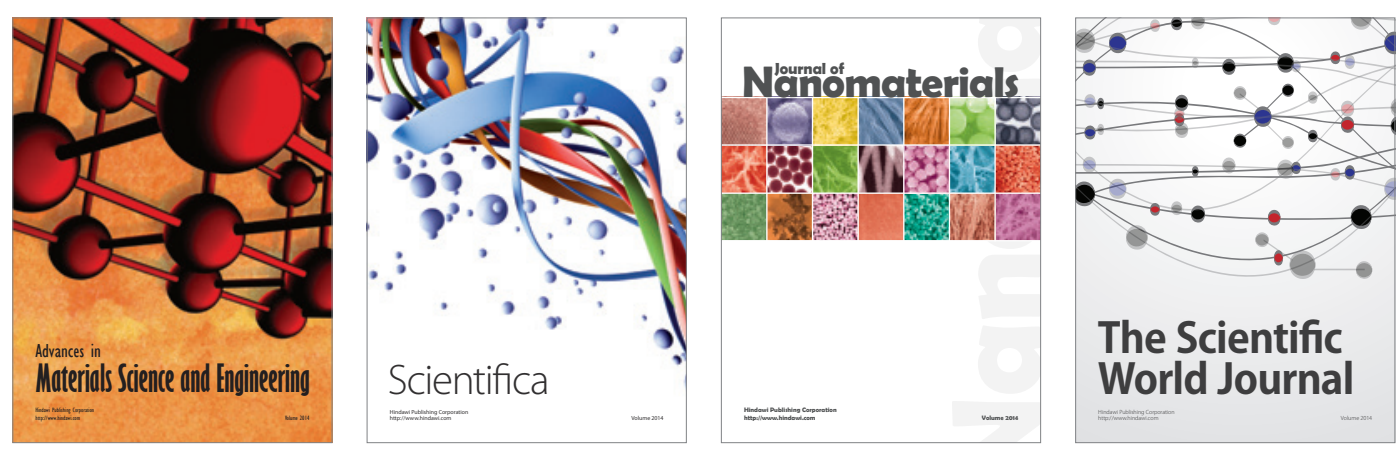

\section{The Scientific World Journal}
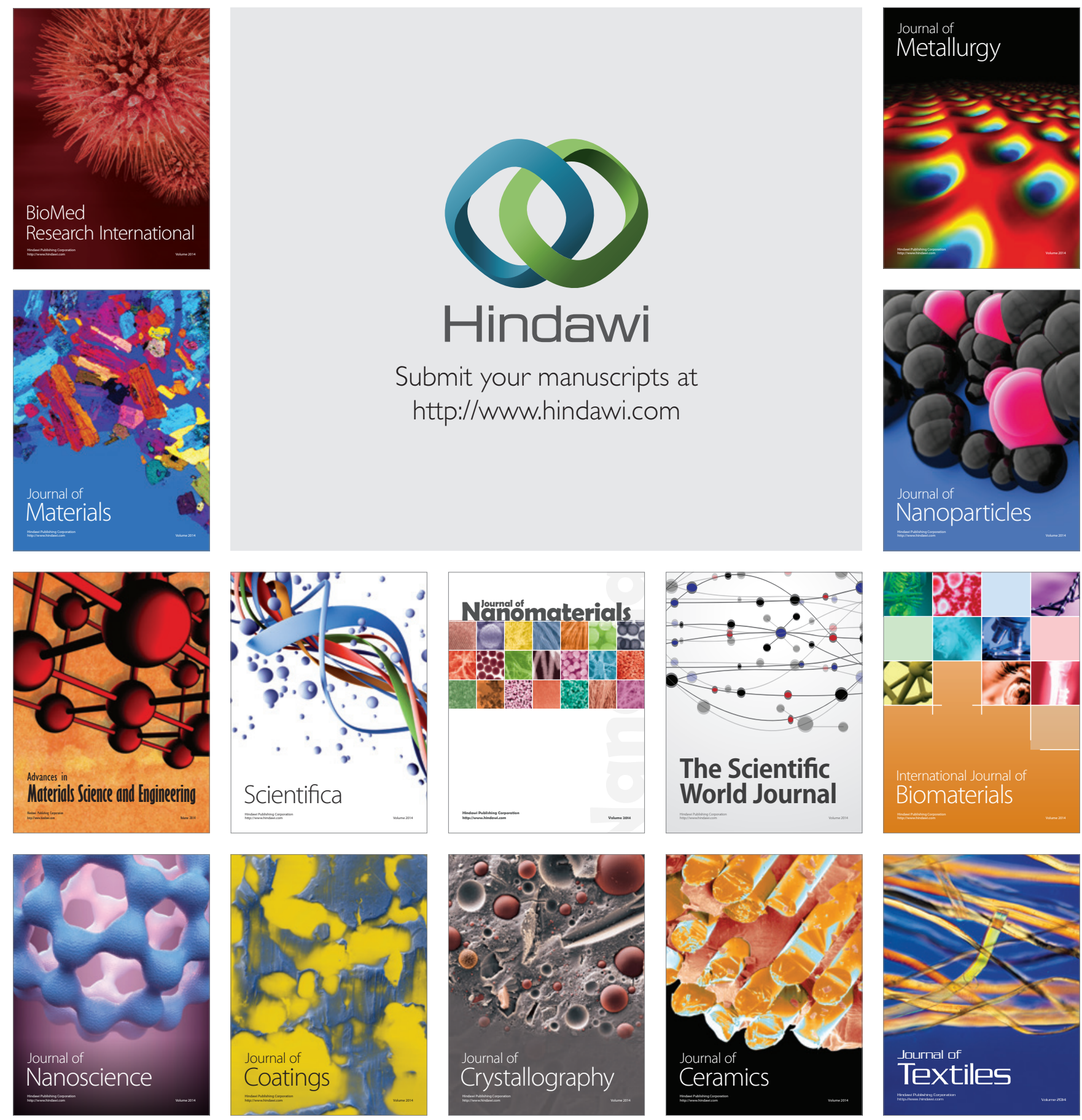